\title{
LA IRRUPCIÓN DEL REALITY GAME EN LA TELEVISIÓN ESPAÑOLA Y SUS EFECTOS SOBRE LOS CONCURSOS (2000-2005)
}

\author{
THE EMERGENCE OF THE REALITY GAME ON SPANISH \\ TELEVISION AND ITS EFFECTS ON QUIZ SHOWS (2000-2005)
}

Enrique Guerrero: Facultad de Comunicación. Universidad de Navarra enrique.guerrero@un.es

\section{CURRÍCULUM VITAE}

Se especializó en 2007 en Entertainment and Media Management por la Universidad de California en Los Ángeles (UCLA) y, en 2009, obtuvo el grado de doctor en Comunicación Audiovisual con premio extraordinario por la Universidad de Navarra, donde es profesor de las asignaturas Gestión de contenidos y Producción y guión de entretenimiento. En esta misma Universidad, colabora desde 2010 como secretario general del Congreso Internacional de Comunicación. Previamente, había desarrollado su actividad profesional en Tele 5, cadena para la que trabajó en el área de producción de varios programas, tras un periodo de prácticas profesionales en otros medios como Onda Cero y Antena 3.

Además de su labor docente, realiza tareas de investigación y consultoría en el área del entretenimiento audiovisual. Entre sus publicaciones, destaca como coeditor de Los desafíos de la televisión pública en Europa (Eunsa, 2007) y de Los jóvenes y el nuevo escenario de la comunicación (Eunsa, 2008), y como autor del libro El entretenimiento en la televisión española. Historia, industria y mercado (Deusto, 2010, en imprenta). 


\title{
RESUMEN
}

En el año 2000, tras un periodo de auge de las series de ficción nacionales, los contenidos de entretenimiento volvieron a copar el prime time de las cadenas de televisión y los primeros puestos en el ranking de audiencias. La irrupción de un nuevo género híbrido, el reality game o docu show, tuvo importantes consecuencias para el mercado televisivo español tanto desde la perspectiva de la producción como de la programación. Debido al considerable componente de juego y competición que integra este contenido, el concurso fue el género de entretenimiento que en mayor medida sufrió la competencia del reality game en las parrillas de programación. Este artículo analiza la oferta de ambos contenidos en la televisión española durante los primeros cinco años de convivencia, así como las consecuencias derivadas del nacimiento de un nuevo género.

\section{PALABRAS CLAVE}

Televisión - Entretenimiento - Reality game - Docu show - Concurso

\begin{abstract}
In 2000, after years of success of Spanish TV fiction series, entertainment contents went back to prime time and topped rating rankings. A new hybrid genre, the reality game or docu show, burst in and it had deep consequences for the television market from the production and the programming perspectives. Given that this content has a considerable component of game and competition, the quiz and the game show were the worst hit genres by the success of the docu show. This article analyzes the offering of these contents in the Spanish television since the premier of the first reality game, Big Brother, in 2000, and its consequences.
\end{abstract}




\section{KEY WORDS}

Television - Entertainment - Reality game - Docu show - Quiz show - Game show

\section{ÍNDICE}

1. Introducción

2. El reality game

2.1 Tele 5

2.2 TVE 1

2.3 Antena 3

3. El concurso

3.1 Tele 5

3.2 TVE 1

3.3 Antena 3

4. Conclusiones

5. Bibliografía

TEXTO:

\section{Introducción}

En el año 2000, diez años después del nacimiento de las cadenas privadas de televisión, el mercado televisivo español se había consolidado sobre la base de una competitiva industria de producción independiente, aunque su proceso de 
(2000-2005), se produjeron importantes cambios que modificaron radicalmente tanto el mercado como la industria de la televisión en España: 1) Un crecimiento constante de la demanda de contenidos de producción propia externa que propicia la creación de centenares de productoras. La tabla 3.1 compara el número de productoras en activo y la cantidad de tiempo y de programas producidos en las temporadas 19992000 y 2004-05.

Tabla 1. Producción independiente en las temporadas 99-00 y 04-05

1999-2000

95

181

12.355
2004-05

PRODUCTORAS

PROGRAMAS

TIEMPO (Horas)
160

296

17.529

Fuente: Elaboración propia a partir de datos de GECA.

2) El liderato del mercado televisivo español pasa de manos de TVE 1 a Tele 5, vuelco que se produce en la temporada 2004-05 tal como se aprecia en el gráfico 1. Esta situación se mantendrá hasta 2009, cuando La 1 recupera la primera posición.

Gráfico 1. Evolución del share de las principales cadenas entre las temporadas 19992000 y 2004-05 


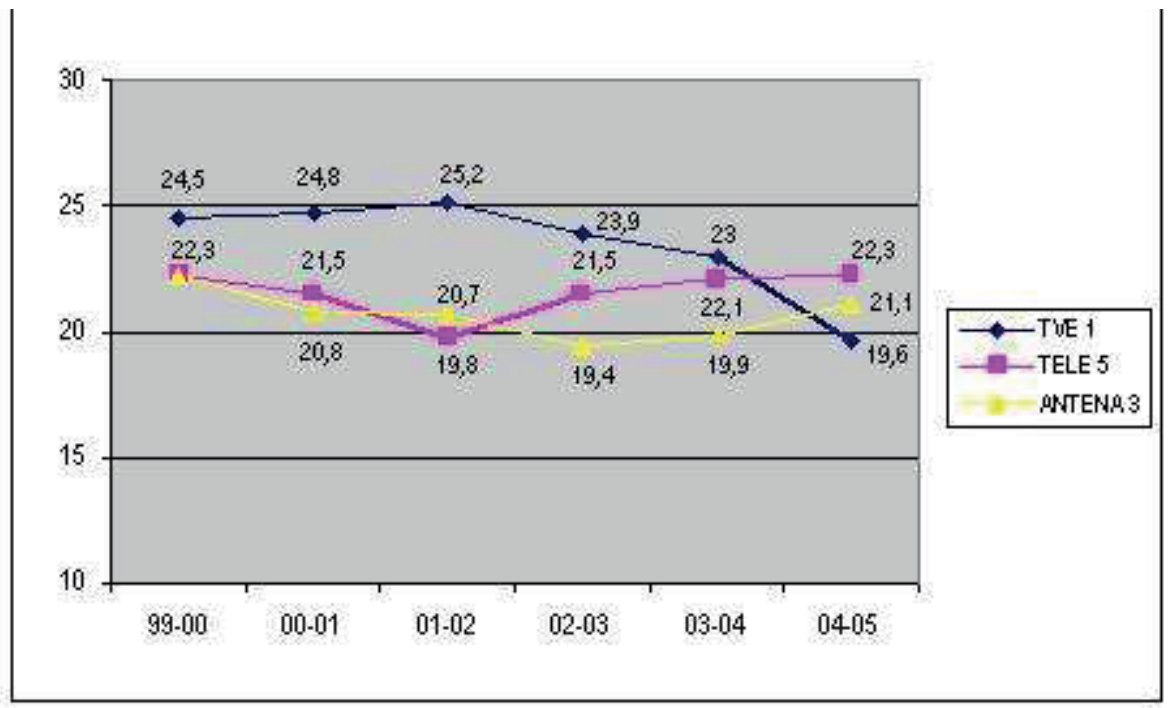

Fuente: Elaboración propia a partir de datos de GECA.

3) Se incrementa la oferta de contenidos audiovisuales en múltiples plataformas. En el año 2005, el Gobierno concede nuevas licencias de TDT, además de una licencia analógica. A esta oferta hay que añadir la disponible a través de otras vías de distribución como el cable, el satélite o el ADSL, y plataformas en auge como Internet y el teléfono móvil.

En cuanto a los contenidos, a mediados de la década de los 90, los géneros de entretenimiento habían sido desplazados del prime time de los días laborales, dominado desde entonces por las series de ficción nacionales. Sin embargo, en el año 2000, el entretenimiento volvió a ser el protagonista de la parrilla televisiva como consecuencia del éxito de audiencia de un nuevo contenido televisivo. El reality game se extendió por todas las franjas en forma de programa independiente y como sección dentro de otros espacios.

De esta forma, desde que el 23 de abril de 2000 Tele 5 estrenará la primera edición de Gran Hermano, toda su oferta televisiva giró en torno a este formato, que situó a esta 
Antena 3 y TVE también decidieron apostar por el reality game, contenido que influyó de forma decisiva en las estrategias de programación y producción de las cadenas durante el lustro que abarca este artículo y que supuso el inicio del auge de los contenidos multimedia.

Los programas de entretenimiento adquirieron relevancia, no sólo por el éxito de audiencia, sino también por razones de índole económica, en parte debido a la crisis publicitaria iniciada a comienzos de la década. Las cadenas optaron por contenidos que ofreciesen un bajo coste de producción o una elevada cantidad de tiempo de emisión. Así lo recoge El anuario de la televisión de 2005 (GECA, 2005: 120): “Las cadenas de televisión apuestan por géneros que proporcionen un alto número de horas de emisión, ya sea a través de formatos de bajo coste (concursos, magacines, divulgativos) o mediante otros más caros ('docu-shows') pero que ofrecen una gran rentabilidad".

A continuación, analizaremos los reality games o docu shows producidos por las principales cadenas nacionales, así como uno de los géneros de entretenimiento que, a priori, debía sufrir en mayor medida su competencia: el concurso. Debido al importante componente de juego y competición que integra en su fórmula el propio reality game, al concurso se le planteaba un gran reto.

\section{El reality game}

Una de las características del nuevo modelo televisivo es la hibridación de contenidos, y el docu show o reality game es una prueba fehaciente de ello. Si bien no existe unanimidad en torno a su denominación, debido a su origen híbrido, hemos optado por estos términos por hacer referencia directa a su contenido.El primero de ellos remite a la aplicación de técnicas narrativas documentales al reality 
producido mediante el empleo de recursos como la grabación constante del acontecimiento, propio del documental, para, posteriormente, narrarlo como una historia dramática. El segundo término, reality game, se refiere a la combinación del reality show con el concurso, más en concreto con el game show, contenido que aporta tensión gracias a su elevada dosis de competición. Ambas denominaciones han sido empleadas tanto por teóricos como por analistas del medio, de modo que aquí son recogidas de forma simplemente referencial y sin ánimo de profundizar en un estudio pormenorizado de los géneros televisivos y sus denominaciones 1.

Son múltiples las variantes del docu show que encontramos en las parrillas de programación de las cadenas españolas: encierro-convivencia (Gran Hermano, Tele 5), formación-superación (Operación Triunfo, TVE 1 y Tele 5), supervivenciahumillación (Supervivientes, Tele 5 y Antena 3 ) y coaching-utilidad (Cambio radical, Antena 3) (Pedrero Esteban, 2008: 51-53).

La cadena de televisión que introdujo este contenido en las parrillas españolas fue Tele 5, cuyo éxito de audiencia influyó en las decisiones de producción y programación del propio canal y de los competidores durante los años posteriores al estreno de Gran Hermano. Este espacio marcó un hito en cuanto que significaba el nacimiento de un nuevo género televisivo. Así lo explica Gloria Saló, ex-directora del departamento de nuevos proyectos de Tele 5: “Un programa que ha sido denominado con múltiples vocablos: human show, psicodrama, docu game, docu show, watercooler show, reality-concurso... Todas estas denominaciones no hacen más que confirmar que un nuevo género televisivo ha nacido y que el desconcierto es tal que ni siquiera se ponen de acuerdo en cómo definirlo" (Saló, 2003: 105). 
El 23 de abril del año 2000 comenzó la primera edición de Gran Hermano, adaptación española del polémico formato holandés Big Brother, realizada por Zeppelin TV, del Grupo Endemol. Este programa hacía realidad, aunque de forma muy limitada, la historia que George Orwell plasmaba en su obra 1984, en la que un "Gran Hermano" vigilaba mediante videocámaras los movimientos de los ciudadanos, carentes de verdadera libertad en una sociedad férreamente controlada.

En su primera traducción televisiva en España, diez concursantes permanecían encerrados durante noventa días en una casa, en la que cada rincón estaba controlado por alguna cámara, y en la que tenían que desarrollar pruebas diversas. Tras un proceso de nominaciones y expulsiones, basados en última instancia en los votos de la audiencia, el último en salir se proclamaba ganador y recibía un premio de 20 millones de pesetas (120.202 euros). Con el transcurso de los años, estas cifras y las reglas de convivencia fueron modificándose según convinieron a los intereses de la cadena y de la productora.

Desde el punto de vista de la producción, la realización de este programa resultaba tremendamente compleja, dado que exigía un trabajo continuo de 24 horas, que obligaba a un estricto sistema de selección de imágenes. Todo el proceso se llevaba a cabo en una nave que integraba tanto la casa-plató como el control de realización, lugar desde el que se procesaba todo el material generado durante días y noches.

Además, este formato híbrido también incorporó un elemento decisivo prestado de la ficción, la serialización, cuyos patrones de producción adoptó. Al igual que cualquier ficción televisiva estructurada en capítulos, Gran Hermano exigía la narración de una historia, protagonizada por unos personajes, y compuesta por una serie de tramas entrelazadas. Esas tramas eran construidas a partir de los conflictos 
propiciados por las actividades concebidas por los guionistas del programa.Todo lo que sucedía en la casa-plató era filtrado mediante dos realizaciones paralelas en directo y registrado en formato digital. En el control de realización, siempre estaban presentes dos redactores que seguían atentamente ambas realizaciones. A la vez que eran grabadas, los redactores describían su contenido y las subdividían marcando una serie de puntos de referencia según el inicio y el fin de los acontecimientos ocurridos y de su grado de interés. Este material era el empleado por los guionistas para la narración de las historias en los sucesivos programas distribuidos por la parrilla y que daban forma a Gran Hermano 2.

En el número 6 de la revista oficial del programa, publicada en julio de 2000, se describía este proceso: “El guionista hace una primera selección de contenidos, y los marca con un punto de entrada [in] y uno de salida [out] de la historia. Luego prepara una segunda selección, más detallada, según la importancia de los contenidos. Así nos quedamos con lo más relevante de la historia. El editor trabaja sobre la base de datos definitiva que ha fijado el guionista y su tarea consiste en digitalizarlo, es decir, dotar a la historia de movimiento [...] Introducimos audio y vídeo por ordenador, es decir, sonidos e imágenes para que la historia sea visual y tenga dinamismo [...] A cada "historia" individual [...] se le pone un nombre. De esta forma nos juntamos con varias "historias" y clips con las que se realiza el montaje bruto junto con el realizador [...] Por la noche, el coordinador de guionistas repasa el montaje del día y añade posibles cambios o nuevos acontecimientos de importancia que han ocurrido en la casa. Por la mañana, el jefe de realizadores repasa el montaje final y pule los últimos trazos añadiendo música, ráfagas, cabecera y créditos" (Lacalle, 2001: 152).

La digitalización de las imágenes facilitaba y abarataba el trabajo, pues eliminaba todos los costes derivados de un almacenaje físico del material. El coste de la primera 
que el 25\% fue pagado por Quiero TV -plataforma de TDT de pago desaparecida- y Vía Digital -plataforma de televisión por satélite fusionada con Canal Satélite Digital en Digital +- en concepto de cesión de los derechos de emisión, Gran Hermano tuvo un coste para Tele 5 de 11 millones y medio de pesetas al día (69.116 euros). Esta cifra resulta una cifra menor si tenemos en cuenta que se convirtió en la cadena líder durante la emisión del programa y dada la gran variedad de fuentes de ingresos que propició este formato: publicidad convencional, votaciones por línea telefónica, revista, juegos, videojuegos, canales temáticos, música, una película -El gran marciano-, subastas del equipamiento de la casa, etc. Además, Tele 5 se apropió de los derechos de imagen de los concursantes durante un año, que como contrapartida percibían una cantidad económica mensual, y que eran gestionados por una agencia creada específicamente para ello.

Uno de los principales aciertos del programa residió en su estrategia de marketing, que empleó diversas plataformas de forma coordinada construyendo un relato unitario, multimedia e interactivo, que encontró su punto fuerte en Internet. Mikel Lejarza, quien por entonces era director general de Tele 5, explica las principales aportaciones del formato en este sentido: “Por primera vez, un programa permite su emisión en un canal temático en televisión de pago, una web en Internet, un programa de televisión en abierto, un magacín, un debate. Es un programa que permite muchas más ventanas que otros formatos" (Saló, 2003: 107).

Desde el punto de vista de la programación, Gran Hermano fue un revulsivo en cuanto que condicionó toda la oferta de Tele 5 y la de la competencia. Toda la parrilla giraba en torno al programa, que se distribuía en distintas unidades a lo largo del día, en forma de galas, resúmenes, conexiones en directo y secciones dentro de otros "programas satélite". De esta forma, Tele 5 consiguió extender el éxito de este espacio a toda su oferta mediante relaciones sinérgicas. Gran Hermano se convirtió 
programas del canal. La primera edición de este reality game se saldó con un 49,3\% de share y 8.356.000 espectadores, llevando a la cadena a ocupar el liderato durante los meses de mayo y junio del año 2000 con una cuota de pantalla superior al 25\%. Tele 5 estrenó la segunda temporada en marzo de 2001, y lo seguirá haciendo año tras año durante la siguiente década hasta convertirse en una de los canales europeos que más veces lo han emitido (Lacalle, 2001: 139-211; Saló, 2003: 104-125; Huerta Floriano, 2008: 125-138; GECA, 2001: 9 y 221-238).

Gran Hermano se convirtió en un killer format o "formato asesino", contenidos que se caracterizan por actuar a modo de motor de la programación garantizando la fidelidad de la audiencia y creando marca en torno al acontecimiento televisivo. En El anuario de la televisión 2004, se recogen sus principales características: "Sus rasgos definitorios se encuentran en los efectos que provocan sobre las parrillas televisivas, a las que imprimen su fuerza y a las que ceden su elevado poder de convocatoria. Dotados de una enorme capacidad de expectación, se convierten en sólidos cimientos de la programación e introducen nuevos mecanismos de fidelización de los espectadores" (GECA, 2004: 81-82).

Tras el éxito alcanzado, Tele 5 continuó apostando por el reality game. En septiembre de 2000 estrenó Supervivientes: Expedición Robinson, adaptación del formato Survivor de la productora sueca Strix, realizado en España por Globomedia. En un principio, la producción de este espacio se llevó a cabo para TVE, pero las críticas dirigidas hacia este género, motivadas por la aversión social a Gran Hermano, provocaron un cambio de opinión en los directivos de la cadena pública, que no consideraron adecuado este tipo de contenidos para una televisión estatal. Así las cosas, en junio del año 2000, cuando el programa se encontraba en plena producción -la grabación había comenzado en abril-, TVE decidió anular el preacuerdo alcanzado con la productora. Al final, fue Tele 5 la que adquirió los 
desarrollaba en directo.

La primera edición contenía un mayor componente de game show, al ser prácticamente un juego de supervivencia en un entorno natural que primero enfrentaba a dos equipos y que, posteriormente, se convertía en una competición personal. La segunda temporada de Supervivientes incorporó más elementos del reality, una gala en los estudios de Tele 5 y se desarrolló en directo, movimientos que acercaron este formato a la fórmula de Gran Hermano. Con la inclusión del directo también se corrigió otra de las debilidades de la primera edición: la dificultad de permitir la participación de la audiencia en el desarrollo del concurso mediante el voto. No obstante, sólo se emitían en directo las galas producidas en el plató, incorporándose a modo de reportaje las acciones desarrolladas en el exterior.

En temporadas posteriores, el formato, aunque emitido bajo distintas denominaciones e incluso por varias cadenas -Tele 5 y Antena 3-, incorporó también el directo desde el paraje natural en el que se encontraban los participantes, permitiendo de este modo la interacción con el presentador y los invitados en el plató, e incrementándose sustancialmente la complejidad de la producción (Saló, 2003: 125-128; GECA, 2002: 226-227; GECA, 2003: 35).

En la temporada 2002-03, si bien el reality game continuó disfrutando de buena salud, la ficción mostraba síntomas de evidente recuperación. Ante esta circunstancia, el género evolucionó e integró un contenido en boga: la crónica social sobre famosos. De esta forma, los reality games nacidos esta temporada fueron protagonizados por personajes relativamente populares, corriente iniciada con cierto éxito por Antena 3 (GECA, 2004: 12 y 31). Tele 5 estrenó en marzo de 2003 el polémico Hotel Glamour, reconvertido en Hotel Glam por problemas legales con el título, protagonizado por famosos de bajo perfil y producido por Gestmusic- 
debido a la controversia social suscitada, que provocó la intervención del consejero delegado de la cadena, Paolo Vasile, y la del propio Presidente del Gobierno, José María Aznar (GECA, 2004: 35-36).

Tele 5 siguió apostando temporada tras temporada por diversos reality games, en torno a los que hizo girar su programación. A los títulos ya mencionados, hay que añadir otros como Gran Hermano VIP o La casa de tu vida, ambos producidos por Zeppelin TV (GECA, 2005: 31-33). Esta productora, perteneciendo al grupo Endemol, se especializó en este tipo de contenidos y realizó todos los programas en las mismas instalaciones, logrando amortizar la compleja infraestructura necesaria. El último éxito de Tele 5 en este ámbito se produjo como consecuencia de la recuperación en el verano de 2005 de un formato que ya había triunfado en TVE: Operación Triunfo (GECA: 2006: 70-71). No era la primera vez que Tele 5 testaba en la época estival un reality game musical, pues ya lo había intentado en 2002 con Popstars (Videomedia), formato previo y de corte similar a Operación Triunfo (Gestmusic-Endemol) (Colis, 2002; Saló, 2003: 136-139).

\subsection{TVE 1}

Televisión Española decidió apostar por el reality game desde una perspectiva más apropiada para una cadena pública: la promoción del talento artístico. El formato de Operación Triunfo fue producido para TVE por Gestmusic-Endemol, productora con una amplia experiencia en programas musicales. La fórmula del éxito surgió de la combinación de elementos del reality show, el concurso y el musical. De esta forma, toma del reality la idea de reunir a un grupo de jóvenes en un recinto -una academia en este caso-, bajo la vigilancia permanente de las cámaras; del concurso incorpora la mecánica de la competición y el premio como recompensa; y del musical extrae el contenido. Para la creación de Operación Triunfo, Gestmusic bebe de Gran Hermano, 
grupo musical y que ya triunfaba en los mercados internacionales.

Desde el punto de vista de la programación, la estrategia seguida por la televisión pública fue similar a la ya probada por Tele 5 con Gran Hermano. TVE 1 diseminó distintos espacios de Operación Triunfo por toda su parrilla y alimentó con sus contenidos a numerosos "programas satélite". Más aún, al disponer de dos canales de cobertura nacional, el operador público puso en marcha una estrategia de programación que se servía de ambas plataformas, estableciendo relaciones sinérgicas y de trasvase de audiencia entre ellas. Así, aunque la mayor parte de las producciones de este espacio se programaron en la primera cadena, el segundo canal también emitió diariamente un resumen de lo ocurrido en la academia. Como resultado, ambas cadenas se beneficiaron del éxito del formato y rejuvenecieron el perfil de su público, dotándolo de un mayor valor comercial. Además, Operación Triunfo fue emitido a través del canal internacional de TVE y de un canal temático de pago creado al efecto, que permitía su seguimiento durante las 24 horas del día.

Esta multiplicidad de vías de distribución se enmarca dentro de la estrategia multimedia que integra el formato desde su ideación. Además de los canales de televisión mencionados, el programa tuvo una importante presencia en Internet (web, chats, foros, etc.), y recurrió a las llamadas y a los mensajes de textos enviados mediante el teléfono móvil, para permitir a los telespectadores participar en su desarrollo. En este sentido, Operación Triunfo fue uno de los espacios que, en su momento, permitió unos mayores niveles de interactividad con el público.

También forman parte de esta estrategia multimedia todas las iniciativas vinculadas al merchandising. Operación Triunfo dio lugar a una gran variedad de productos derivados puestos a la venta: álbumes musicales, vídeos, posters, libros, coleccionables, una revista oficial, etc. Más aún, como formato abanderado de la 
como la producción de una película y la realización de giras musicales. Todo ello se tradujo en una gran diversidad de fuentes de negocio que revirtieron en beneficio de la cadena, TVE, y de la productora, Gestmusic-Endemol. Además, una buena porción de la tarta de ingresos fue a parar a Valemusic, discográfica que ganó el concurso convocado para gestionar los derechos de los participantes y producir sus trabajos musicales.

Operación Triunfo se convirtió de esta forma en el killer format de la televisión pública, revulsivo que convulsionó las parrillas de programación y el contenido de las cadenas competidores, que al igual que ocurriera antes con Gran Hermano, no pudieron resistir la tentación de incluir secciones en sus espacios sobre un programa ajeno.

Un formato de esta magnitud conllevaba múltiples dificultades de producción y un elevado coste, difícilmente soportable por la maltrecha economía de TVE. Esta circunstancia obligó a los directivos de la cadena pública a negociar un recorte de los gastos de producción y a ceder los derechos derivados de la explotación discográfica. Dada la envergadura del proyecto y el riesgo económico que representaba tanto para el operador como para la productora, llegaron a un acuerdo que suponía compartir los riesgos: Gestmusic-Endemol no vendió a TVE Operación Triunfo por un precio cerrado, sino vinculado a los porcentajes de audiencia. Ello quedó reflejado en las cifras que costaba producir este espacio, cuyo presupuesto ascendió más de un 80\% desde el estreno de la primera edición, en octubre de 2001, a la firma del contrato de la segunda temporada, en septiembre de 2002. Mientras que la televisión pública pagó unos 6 millones de euros por la primera edición, la segunda le costó una cantidad superior a los 11 millones. La tabla 2 registra este incremento. 
TEMPORADA 01-02

\section{GASTOS INICIALES \\ PRODUCCIÓN GALAS}

RESÚMENES
1,5

4,3

0,45
TEMPORADA 02-03

1,3

9,6

1,1

Fuente: ABC (06/02/2003).

Nota: Cifras en millones de euros.

El crecimiento de los costes de producción se percibe especialmente en las partidas referidas a los resúmenes diarios y a las galas, aunque en este caso también se produce un incremento del número de programas contratados, que pasa de 14 en la primera temporada a 21 en la segunda. No obstante, debido al éxito de audiencia, TVE suscribió dos ampliaciones del contrato de la primera edición con el objetivo de producir nuevas galas y aprovechar el éxito de audiencia, costes no incluidos en las cifras anteriores. En total, la cadena pública contrató 9 galas adicionales, oscilando el precio de cada una entre los 174.000 y los 450.000 euros, cifra aproximada a lo que le costaría cada programa de prime time en la segunda temporada.

A pesar de su elevado coste de producción, Operación Triunfo fue un programa rentable para TVE. Su primera edición le reportó a la cadena pública unos ingresos superiores a 23 millones de euros que se repartieron de la siguiente forma (tabla 3): 


\section{EUROS}

PUBLICIDAD CONVENCIONAL

LLAMADAS

VENTAS DE CD

PATROCINIOS

VENTAS A OTRAS TV

MENSAJES MÓVILES

OTRAS FORMAS PUBLICIDAD
16.500 .000

2.600 .000

1.938 .000

931.000

251.000

93.000

847.000

Fuente: ABC (22/02/2002).

TVE acertó al contratar la producción de este formato, que previamente había sido rechazado por Antena 3 y Tele 5. Sin embargo, erró al intentar exprimirlo al máximo, provocando un cansancio en la audiencia y un desgaste de la fórmula. Una prueba de ello es que entre las diversas producciones agrupadas bajo la denominación de Operación Triunfo y secuelas posteriores como Triunfomanía, la primera temporada se extendió desde el 22 de octubre de 2001 hasta el 4 de junio de 2002. Ello implica que se mantuvo en antena durante todo el curso televisivo, con la consiguiente sobreexplotación del formato. Además, a estas emisiones hay que añadir aquellas vinculadas a Eurovisión, pues mientras Operación Triunfo se programó en TVE, sirvió como plataforma de selección del representante español en el festival europeo. En la segunda temporada ocurrió algo similar, al ser programados los castings en la segunda cadena en septiembre de 2002, para luego encadenar con el grueso del programa y su posterior secuela, en esta ocasión bajo el título de Generación OT, cuyas emisiones finalizaron en junio de 2003. 
programa tras sus tres temporadas en TVE: 44,2\%, 36,8\% y 23,3\%. Después de más de un año de descanso, Operación Triunfo fue recuperado con éxito por Tele 5 en 2005 (Cebrián Herreros, 2003; Saló, 2003: 136-150; GECA, 2003: 33-34 y 108; GECA, 2004: 32-33 y 134; GECA, 2005: 32-33 y 130; Álvarez, 22/02/2002; Álvarez, Navas, 05/03/2008).

\subsection{Antena 3}

Si Tele 5 había inaugurado la época dorada del reality game con Gran Hermano, y TVE había confirmado su auge con Operación Triunfo, Antena 3 corrió peor suerte en su apuesta por este contenido televisivo. Esta cadena confió la producción de su primer docu show a Gestmusic, que adaptó un formato ideado por Endemol, productora propietaria también de Big Brother. El Bus, título del programa de Antena 3, era en realidad una versión itinerante de Gran Hermano diseñada por los mismos creadores. Sin embargo, sus resultados de audiencia fueron muy diferentes: en su única temporada, emitida entre septiembre y diciembre del año 2000, las galas de prime time obtuvieron una cuota de pantalla media del 24,1\%, que si bien superaba en casi cuatro puntos la media de la cadena, resultó un fracaso respecto a las expectativas levantadas.

Lejos de convertirse en un killer format que sirviese de motor de toda la parrilla, sus diversas producciones diseminadas a lo largo de la programación, así como las secciones dentro de otros espacios, no obtuvieron el respaldo de la audiencia, con cifras de share entre el 13\% y el 18\%. Los telespectadores vieron en El Bus una copia de Gran Hermano, castigando de esta forma su falta de originalidad.

Antena 3 intentó emular la estrategia de programación de Tele 5 consiguiendo un efecto contrario al deseado, creando una excesiva dependencia de su parrilla respecto 
media de toda su oferta gracias al impulso dado por las distintas producciones de Gran Hermano, Antena 3 sufrió una pérdida de telespectadores al hacer pivotar su programación sobre un formato incapaz de generar fidelidad (GECA, 2004: 82-83).

El Bus tuvo un alto coste para Antena 3, que pagó a Gestmusic-Endemol una cifra superior a los 1.000 millones de pesetas (6 millones de euros), a los que hay que sumar los casi 500 millones ( 3 millones de euros) pagados por las plataformas digitales Quiero TV (TDT) y Vía Digital (satélite) -la primera de ellas desaparecida, y la segunda fusionada con Canal Satélite Digital en Digital +-. El elevado coste del programa encontraba su explicación en la complejidad de la producción, dado que fue necesario construir un autobús de dos plantas equipado para servir de plató de televisión, unido a un control de realización móvil en forma de remolque situado en la parte trasera. Además, todas las semanas, la gala de prime time se celebraba en una ciudad distinta, por lo que requería montar y desmontar el escenario y todo el equipamiento técnico continuamente (Saló, 2003: 128-130; GECA, 2002: 226-228, 344 y 362).

A pesar de este tropiezo, Antena 3 insistió en encontrar un reality game de éxito, de modo que siguió apostando por este género. Así las cosas, en el año 2002, esta cadena encomienda a Zeppelin TV, también del Grupo Endemol, la producción de dos docu shows: Confianza ciega y Estudio de actores.

El primero de ellos, en el que se ponía a prueba la fidelidad de las parejas participantes, se emitió en diferido, convirtiendo el material grabado en dos semanas en un relato dividido en capítulos semanales que se mantuvo tres meses en antena. $\mathrm{Al}$ igual que en programas como Supervivientes, Confianza ciega transcurría en un escenario natural, en este caso un resort hotelero, y no en un estudio de televisión, tendencia que se acentuó en los años siguientes. La aceptable audiencia del programa (21,2\% de share) hizo posible que Antena 3 lo programara al completo e, incluso, que 
cualquier caso, la controversia generada por el formato no aportó una buena imagen de marca a la cadena, así que no tuvo lugar una segunda edición (Saló, 2003: 135-136; GECA, 2003: 34).

Estudio de actores fue el primer gran fracaso en la televisión española en lo que a docu shows se refiere. Tras el fallido intento de repetir el éxito de Tele 5 y Gran Hermano con El Bus, Antena 3 decidió seguir los pasos dados por TVE y Operación Triunfo con un reality game artístico o de talento y superación. Esta vez, la convivencia de los participantes se desarrollaba en una academia de interpretación, donde asistían a las distintas clases y en la que preparaban las actuaciones semanales para la gala de prime time. Todo estaba planificado para repetir el éxito de la competencia, por tanto, Antena 3 decidió promocionarlo con el objetivo de convertirlo en su ansiado "formato asesino", vertebrando su parrilla en torno a él, y cediendo los derechos de emisión para un canal temático 24 horas. Sin embargo, tras cuatro emisiones con una cuota de pantalla media del 8,8\%, la cadena y la productora llegaron a un acuerdo para cerrar la escuela, con las consiguientes pérdidas económicas derivadas de la cancelación de un proyecto de semejante envergadura, para el que se había construido en exclusiva una nueva academia-plató (GECA, 2003: 34; Martín-Lunas, 28/04/2002).

En 2003, Antena 3 vuelve a fracasar en su empeño con X ti, un formato producido por Zeppelin TV de apariencia similar a Gran Hermano pero de mecánica mucho más compleja, al reconvertir el clásico dating game de búsqueda de parejas en un reality game (GECA, 2004: 36). Sin embargo, este año, por primera vez, es Antena 3 la que toma la iniciativa e inaugura una nueva tendencia: La isla de los famosos fue el primer docu show en el que los concursantes eran personajes relativamente conocidos, aprovechando el creciente interés que despertaban en televisión sus vidas privadas. Su más que aceptable acogida, con un 21,3\% de share, animó a Antena 3 a 
realidad, la reconversión del formato Supervivientes, emitido anteriormente por Tele 5 y también producido por Globomedia. Este mismo formato regresó a Tele 5 en 2006 producido por Magnolia (GECA, 2004: 34-35 y 134).En las temporadas 2003-04 y 2004-05, Antena 3 mantuvo su apuesta por el reality game protagonizado por famosos, pero con resultados cada vez más discretos con títulos como La selva de lo famosos, Aventura en África y La granja, los dos primeros realizados por Globomedia, productora que cobró entre dos y tres millones de euros por cada una de estas producciones 3, y el tercero por Gestmusic-Endemol. Esta última compañía también produjo uno de los últimos fracasos de Antena 3 en este ámbito, El castillo de las mentes prodigiosas, espacio que fue cancelado por sus bajos índices de audiencia tras ser trasladado a la franja de late night (GECA, 2005: 32 y 34; GECA, 2006: 71). El reality game de aventuras implica una producción extraordinariamente complicada, especialmente cuando es realizado en directo, dado que exige un trabajo continuo de 24 horas. Víctor Martín, productor ejecutivo de programas de entretenimiento de Globomedia, explica la mecánica de producción de un programa como Aventura en África:

“En Kenia, había un equipo de cámaras y redactores que se ocupaban del Día a día. Todo creaba un flujo de información e imágenes. Las cintas iban llegando para la edición a la vez que se estaba grabando. Teníamos cinco salas de edición y una de gráficos, que trabajaban día y noche en tres turnos. Al ser una grabación continua, teníamos varios realizadores. Había dos días de galas a la semana y todos los días se emitía un resumen. El resumen se grababa por la mañana y se emitía en España al mediodía. Para ello, se editaba corriendo y se enviaba vía satélite. Llegado el momento todo está mecanizado.Conforme van llegando las cintas procedentes de los magnetos de las cámaras instaladas en los campamentos, se introducen en unos magnetoscopios conectados a un sistema informático llamado Logger. Este sistema reproduce la cintas en tiempo real a la vez que los documentalistas o "logueadores" 
registra las anotaciones unidas a las imágenes, con unos códigos de tiempo, que luego son revisadas por los guionistas y la dirección para construir la historia"4. Así como el espacio producido en el plató se realizaba de forma conjunta entre la productora y la cadena, "la parte del programa desarrollada en el extranjero era realizada completamente por Globomedia, a excepción de los enlaces, gestionados por Antena 3" 5. La emisión en directo de las galas requería una compleja coordinación entre los dos equipos de realización, el del exterior y el del estudio de televisión.

1- Desde El anuario de la televisión 2001, el Gabinete de Estudios de la Comunicación Audiovisual (GECA) recoge los datos referidos a este contenido televisivo bajo la denominación de docu show. En su edición del año 2003, autores como José María Baget Herms o Emili Prado tratan la evolución de este género, máximo exponente de la hibridación, $\mathrm{y}$, entre otros, emplean los términos mencionados: docu show en el primer caso, y reality game en el segundo (como un subgénero del info-show según Euromonitor). Véase BAGET HERMS, José María: Del docudrama a "Operación Triunfo". En: El anuario de la televisión 2003. Madrid, 2003. GECA. Págs. 88-96; y PRADO, Emili: La espectacularización de la realidad. En: El anuario de la televisión 2003. Madrid, 2003. GECA. Págs. 178-186.2- Información extraída de la observación directa de la producción de Gran Hermano (temporada 2003-04). 3- Entrevista a Víctor Martín, productor ejecutivo de programas de entretenimiento de Globomedia, 16/06/2008, Madrid. 4- Idem. 5- Idem. 
A finales de la década de los 90, el concurso volvió con fuerza a las parrillas de programación como una pieza estratégica clave, especialmente en el day time. Resurge el interés por el quiz show en la franja de tarde gracias a formatos como Alta tensión o ¿Quiere ser millonario? El éxito de estos programas anima a las cadenas a programar concursos de preguntas y respuestas en el prime time, aunque siempre con un elevado componente de espectacularidad y cierta dosis de game show. Además, incrementaron el valor de los premios para mejorar la competitividad del género frente a otros contenidos (Lacalle, 2001: 66). No obstante, los concursos de gran formato no alcanzaron los buenos resultados de este género en horarios diurnos.

Gráfico 2. Evolución de los géneros de entretenimiento más vistos (96-05)

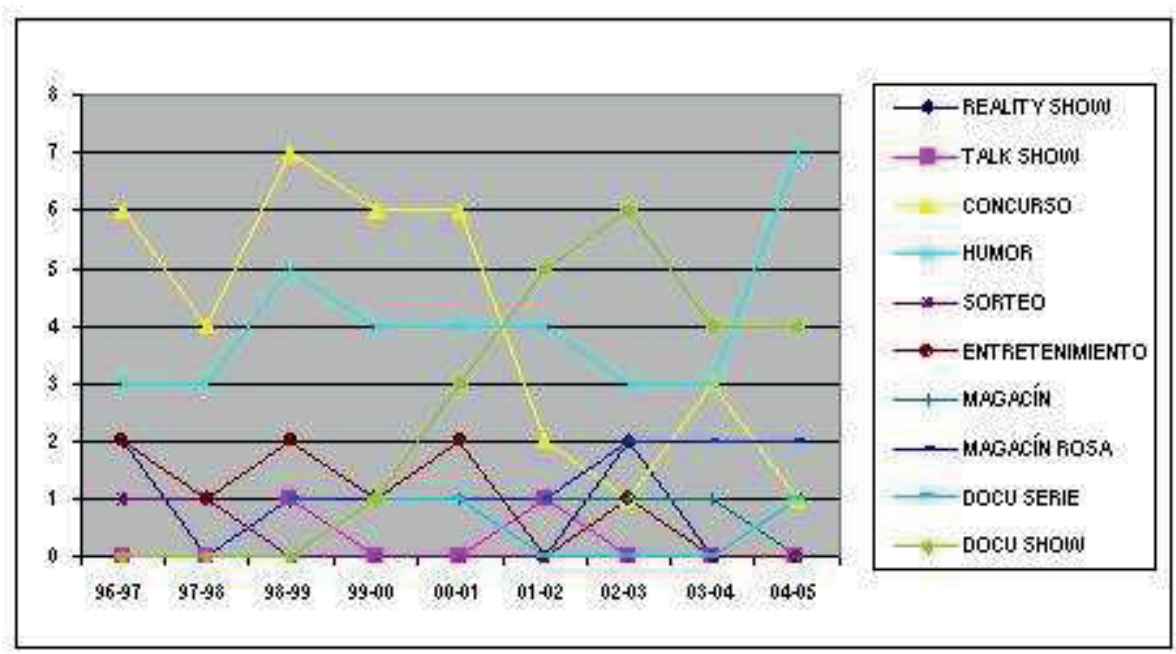

Fuente: Elaboración propia a partir de datos de GECA.

Si bien los contenidos de entretenimiento regresaron a la franja de máxima audiencia de lunes a viernes en el año 2000, esta circunstancia estuvo siempre muy vinculada al éxito del reality game. De esta forma, y a pesar del auge del concurso en la banda de 
vistos por temporadas disminuye a partir de este año, prácticamente, en la misma proporción en la que se produce el ascenso del docu show (gráfico 2).

Aunque se mantienen los buenos resultados de los concursos de day time, con un notable descenso a mediados del primer lustro del nuevo siglo, este gráfico demuestra que, en el prime time, el importante componente de competición y juego que integra el docu show o reality game supone una competencia directa para el concurso.

Veamos a continuación la oferta que de este género han realizado las tres grandes cadenas nacionales en el periodo que nos ocupa.

\subsection{Tele 5}

La firme apuesta de Tele 5 por el reality game y por otros contenidos como la ficción nacional y los programas denominados de "crónica rosa", ejes temáticos de las parrillas durante estos años, apenas deja huecos en su oferta de prime time para el concurso (GECA, 2006: 11).

¿Quiere ser millonario? es el único que ocupa un lugar preferente en la franja de máxima audiencia, programado los jueves y los fines de semana. No obstante, el éxito de este formato en prime time queda pronto ensombrecido por Gran Hermano. Este hecho, unido al desgaste al que Tele 5 somete al concurso en la temporada 200001, al programarlo ininterrumpidamente, conduce en el curso siguiente a la cancelación de este programa, que hubiese podido tener un mayor recorrido si la cadena hubiera reducido su presencia en la parrilla (GECA, 2002: 172, 232 y 234).

La confianza depositada por Tele 5 en este género queda reflejada en el listado de concursos que este canal programa durante el periodo que nos ocupa. Al 
euromillón, que sustituyó al anterior en el access prime time diario, aunque no logró mejorar sus resultados. En esta misma franja, también fueron programados Decisión final (01-02), El legado (verano de 2002), La quinta esfera (02-03 y 03-04), Allá tú (0304/07-08) y, en fin de semana, el concurso cultural Tiempo límite (00-01). Para la realización de estos programas, Tele 5 optó, según el caso, por diferentes fórmulas de producción. Por ejemplo, mientras que ¿Quiere ser millonario? y La quinta esfera fueron producidos internamente por la cadena con sus propios recursos técnicos y humanos tras adquirir los correspondientes derechos; Decisión final y Allá tú fueron realizados por las productoras Boomerang TV y Gestmusic-Endemol respectivamente.

De los concursos emitidos por Tele 5 desde el estreno de ¿Quiere ser millonario? hasta 2005, sólo Allá tú obtuvo el respaldo firme de la audiencia. Todos estos formatos pertenecían a una variante del concurso, al quiz show, aunque con un gran componente de juego, con la única excepción de Allá tú, ajustado más bien a la fórmula del game show (GECA, 2002: 172 y 232-236; GECA, 2003: 27; GECA, 2004: 28 y 94; GECA, 2005: 39; GECA, 2006: 76).

A pesar de los tropiezos mencionados, Tele 5 mantuvo la confianza en el concurso como una pieza estratégica de su programación durante estos años. La flexibilidad del género le permitió realizar los ajustes oportunos en su parrilla sin costes elevados, y su capacidad para atraer a una audiencia amplia y hacerla participar en el juego, propició que esta cadena recurriese al concurso para poner en práctica una de las más clásicas estrategias de programación: Lead-in. Esta práctica no consiste más que en contar con un espacio atractivo, sencillo y breve dirigido a un público variado y capaz de acumular audiencia y de trasvasarla de la franja de acceso al programa principal de prime time (Cortés Lahera, 1999: 230). 
El primer canal de TVE continuó emitiendo en su franja vespertina concursos como Waku Waku, programado los domingos, y la versión renovada y diaria de El precio justo. Ambos formatos comenzaron a sufrir cierto desgaste y a obtener cifras de audiencia muy discretas (GECA, 2002: 234). En sustitución de El precio justo, programó en 2002 El gladiador, realizado por Europroducciones, un quiz show dotado de cierta dosis de espectacularidad al enfrentar a los concursantes con el público. No obstante, debido a sus bajos índices de audiencia (14,9\% de share), más de diez puntos por debajo de la media de la cadena, se emitieron tan solo la mitad de los 65 capítulos contratados, aunque la cadena pública abonó a la productora el total pactado, es decir, 390.658 euros (GECA, 2003: 36 y 198; T.B.G., 04/07/2002; Fernández, 04/01/2004).

Para ocupar el hueco dejado por este espacio, TVE apostó por un quiz show de probado éxito internacional y que respondía a una tendencia en los concursos de moda: la agresividad. De esta forma, un género tan clásico como el concurso buscaba una vía de revitalización y de acercamiento al contenido en auge: el reality game. La primera cadena programó El rival más débil, adaptación española del formato británico de The Weakest Link, producido por Splendens Ibérica. En este espacio, los nueve concursantes compartían protagonismo con el presentador, cuya figura era esencial en el desarrollo del juego y su papel uno de los elementos definitorios del formato. El conductor no era un mero árbitro, sino que se convertía en un antagonista más al que se tenían que enfrentar los participantes, quienes además de responder a las preguntas y de votar a sus oponentes más vulnerables, tenían que soportar los comentarios impertinentes del presentador para optar a un premio máximo de 7.200 euros. Aunque el programa no resultó muy eficaz y su audiencia siempre se situó por debajo de la media de la cadena, se mantuvo en la parrilla de TVE 1 hasta 2003, para ser trasladado en 2004 a la segunda cadena del operador 
2005: 132).

En enero de 2003, el hueco dejado por Waku Waku los domingos por la tarde fue ocupado por Mi planeta, otro concurso vinculado al medioambiente producido por El Mundo TV. Debido a su discreta acogida, fue sustituido en junio de ese mismo año por Jimanji Kanana, una versión renovada de Waku Waku, ambos espacios ideados y producidos por la misma persona, Narciso Ibáñez Serrador, a través de su empresa Prointel (GECA, 2004: 94, 133 y 136; GECA, 2005: 132).

TVE dirigió su mirada una vez más hacia el mercado británico y en la temporada 2004-05 importó el concurso El enemigo en casa, programado de lunes a viernes en la franja de tarde. No era la primera ocasión en que se adaptaba un formato mixto que combinaba elementos del quiz y del game show: entre los cinco concursantes había un infiltrado que conocía las respuestas, y si el resto de participantes no lograba desenmascararlo, se llevaba el premio final. Por tanto, al clásico concurso de preguntas se le añadía un juego de estrategia como mecanismo para generar intriga e implicar al telespectador, que también debía descubrir quién era el infiltrado. No obstante, el programa no obtuvo el respaldo de la audiencia y fue trasladado a la segunda cadena, como ocurrió con otros espacios como El rival más débil (GECA, 2006: 76; RTVE, 22/04/2005).

Como ya se ha mencionado, el contenido de entretenimiento predominante en el prime time a partir del estreno de Gran Hermano fue el reality game. Sin embargo, el éxito alcanzado en esta franja por otros programas como ¿Quiere ser millonario? en Tele 5, motivó que el resto de cadenas probaran a emitir concursos en el horario de máxima audiencia. 
cadena FOX con el título Greed (avaricia) y adaptado en España por Pearson TV (FremantleMedia), en el que los participantes concursaban primero en equipo y luego de forma individual. Al igual que en ¿Quiere ser millonario?, la escenografía y la iluminación constituían una parte esencial del formato. En su única temporada (0001), este programa alcanzó una cuota de pantalla media del $22,5 \%$, cifra que fue menguando con el paso de las semanas debido, en parte, a un cambio de programación -fue trasladado del jueves al lunes-. TVE pagó a Pearson TV 4,2 millones de euros por la producción de 30 emisiones (Saló, 2003: 103-104; GECA, 2002: 178, 232 y 233; Fernández, 04/01/2004).

Durante el periodo que transcurre entre el año 2000 y el 2005, la cadena pública también programó en prime time otros concursos como el ya mencionado Todo en familia (00-01) o Pequeños grandes genios (01-02 y 03-04), un quiz show producido por Prime Time Communications y protagonizado por niños. En el curso 2003-04, estrenó una nueva versión del clásico Un, dos, tres, aunque en esta ocasión con el título de Un, dos, tres... ¡A leer esta vez!, también producido y dirigido por Narciso Ibáñez Serrador. Por último, en la temporada 2004-05, la cadena pública apostó por dos concursos de habilidades "artísticas": uno relacionado con la canción, Gente de primera (ZZJ), en el que cantantes noveles eran apadrinados por artistas ya consolidados; y otro vinculado a las habilidades para el baile, ¡Mira quién baila! (Gestmusic-Endemol), protagonizado por famosos y que permanece en la parrilla de La 1 hasta que en 2010 se traslada a Tele 5. El concurso de talentos se confirmaba así como una nueva tendencia a mediados de esta década (GECA, 2003: 110; GECA, 2005: 35 y 132; GECA, 2006: 31, 70, 72 y 73).

Además, durante los sucesivos veranos, TVE programó el que por entonces fue el más veterano de los concursos: Grand Prix, game show producido por Europroducciones. 
Durante la segunda mitad de los 90, Antena 3 encontró un filón en los concursos de prime time para el fin de semana, tras el éxito alcanzado por las series de ficción nacional en los días laborales. En la etapa que nos ocupa, esta cadena continuó apostando por esta estrategia. De este modo, siguieron en emisión concursos como Furor, ¿Quién dijo miedo?, La parodia nacional, Lluvia de estrellas, Menudas estrellas y Trato Hecho, y nuevos títulos como Una vez en la vida, Fugitivos en la ciudad, Mujer 10, La noche de los tramposos y Factor Miedo (GECA, 2002: 178, 180, 232, 344-346; GECA, 2004: 132 y 136; GECA, 2005: 133).

Sin embargo, todos los programas estrenados en la franja de máxima audiencia del fin de semana no obtuvieron el respaldo de la audiencia y fueron retirados de la parrilla. No obstante, hubo una excepción, un macro-concurso interactivo emitido a modo de tres especiales con carácter mensual en el que se medían diferentes parámetros como el cociente intelectual, la memoria o la capacidad "amorosa" de los participantes, agrupados según diferentes categorías: profesión, sexo, edad, etc. El gran test fue emitido en la temporada 2002-03 y recuperado en 2005, edición en la que se incluyó una versión on line del cuestionario -en la primera temporada, el test se publicó en medios impresos-, para permitir la participación de la audiencia durante el desarrollo del programa, realizado en directo (GECA, 2004: 36 y 94).

Como se ha mencionado, el concurso de referencia de estos años fue ¿Quiere ser millonario?, por el éxito logrado en el horario de tarde y en el prime time de Tele 5. En un intento de emular a su rival y para sustituir Alta tensión, Antena 3 estrenó en el verano del año 2000 Pasapalabra, cuyo origen se encontraba en el formato británico The Alphabet Game -aunque la versión española era más bien una adaptación del Passaparola del Canale 5 italiano-. Básicamente, consistía en una fórmula mixta a medio camino entre el quiz y el game show donde concursantes 
palabras. Los buenos resultados obtenidos en la franja vespertina frente a ¿Quiere ser millonario? animaron a los responsables de Antena 3 a llevarlo también al prime time. Sin embargo, en este tramo horario, no logró obtener los niveles de audiencia alcanzados por la tarde, debido a que en la franja de máxima audiencia se necesita, normalmente, un mayor grado de espectacularidad.

Algunas de las claves del éxito del programa se encontraban en su sencillez y agilidad, su capacidad para permitir a la audiencia participar en el juego y de incorporarse en cualquier momento al programa, y en su flexibilidad, convirtiéndose en una pieza estratégica del access prime time de Antena 3. Así lo explica Javier Núñez, quien fue director del espacio: “Tiene una estructura perfecta para introducir cambios, porque es un programa de pruebas donde se pueden modificar fácilmente sin que se transforme la estructura interna del programa" (Saló, 2003: 160).

Pasapalabra fue empleado por los programadores de Antena 3 como un programa de acceso cuya principal función no era otra que la de acumular audiencia para trasvasarla a la oferta principal del prime time, según la estrategia de programación conocida como lead-in (Cortés Lahera, 1999: 230). El concurso se mantuvo en emisión hasta 2006, para ser recuperado un año más tarde por Tele 5, cadena que adquirió los derechos de la mano de la productora propietaria del formato en España: Bocaboca (Saló, 2003: 159-161; GECA, 2002: 172, 232 y 235).

Antena 3 recurrió en 2004 al concurso para poner en práctica esta misma estrategia pero dentro del prime time. Además de emitir Pasapalabra como espacio de acceso al programa de noticias de las nueve de la noche, tras el informativo, situó el game show ¿Hay trato?, una versión diaria de Trato hecho producida por Grundy (FremantleMedia). De esta forma, la edición nocturna de Antena 3 Noticias, que había reducido su duración, quedaba flanqueada por dos concursos. ¿Hay trato? servía así de puente y como programa de acceso a la oferta estelar del prime time, 
130).

En 2005, esta cadena se hizo con los derechos del formato Who wants to be a millionaire?, producido y emitido antes por Tele 5, adaptado ahora por la productora Martingala bajo la denominación de ¿Quién quiere ser millonario?, traducción literal del título original. Así las cosas, Antena 3 y Tele 5 se intercambiaron dos concursos que se consideraron desgastados y que continuaron triunfando tras ser renovados en la parrilla rival.

\section{Conclusiones}

Los contenidos televisivos que componen las parrillas de programación de las cadenas van evolucionando según las tendencias vigentes, los gustos de la audiencia y las exigencias del sector. Fruto de la hibridación, en el año 2000, irrumpió en España un nuevo contenido nacido de la fusión de géneros como el reality o el game show y de técnicas propias del documental y de la ficción. Aunque no existe un claro consenso en la industria sobre cómo denominarlo, son generalmente aceptados términos como reality game o docu show, cuyo máximo exponente es Gran Hermano, formato pionero al que siguieron otros como Supervivientes u Operación Triunfo.

Si bien a mediados de los 90, las series de producción nacional coparon los ranking de audiencia y el prime time, relegando a los contenidos de entretenimiento a franjas horarias de menor valor comercial; en el año 2000, la llegada del reality game supuso la reconquista del prime time por parte de los géneros de entretenimiento. Más aún, debido a la técnica de explotación intensiva de los contenidos propia de estos formatos, se extendieron por toda la programación de las cadenas, aportando 
Internet. De este modo, se inició el periodo de auge de los formatos multimedia.

Los programas de entretenimiento adquirieron relevancia, no sólo por el éxito de audiencia, sino también por razones de índole económica. Las cadenas optaron por contenidos que ofrecían un bajo coste de producción o bien una elevada cantidad de tiempo de emisión, como es el caso de los docu shows. No obstante, no siempre puede hablarse de rentabilidad en términos económicos, pues este tipo de contenidos cuenta con sonados fracasos como Escuela de actores o El Castillo de las mentes prodigiosas, ambosde Antena 3, que lejos de incrementar la audiencia media del canal, la hicieron disminuir, y supusieron cuantiosas pérdidas. Y aún menos puede considerarse positivamente su rentabilidad en términos de imagen corporativa, pues la polémica suscitada por formatos como Gran Hermano, Hotel Glam o Confianza ciega, acabaron desgastando la marca de las cadenas. En este sentido, programas como Operación Triunfo, presentados como promotores del esfuerzo y del talento, son una excepción.

En este contexto, el género de entretenimiento que en mayor medida sufrió el éxito del reality game fue el concurso, debido al importante componente de juego y competición que integra en su fórmula el propio docu show.

\section{Bibliografía}

ÁLVAREZ, F. y NAVAS, J. A.: " «Operación Triunfo 2» cuesta a TVE 11,5 millones, un 83\% más que hace sólo un año". En: ABC, 06/02/2003. Disponible en http://www.abc.es/hemeroteca/historico-06-022003/abc/Comunicacion/operacion-triunfo-2-cuesta-a-tve-115-millones-un-83--masque-hace-solo-un-a\%F1o_160367.html. 
ABC, 22/02/2002. Disponible en http://www.abc.es/hemeroteca/historico-22-022002/abc/Comunicacion/tve-recauda-23-millones-de-euroscon-operaciontriunfo_79799.html.

BAGET HERMS, José María: Del docudrama a "Operación Triunfo". En: El anuario de la televisión 2003. Madrid, 2003. GECA. Págs. 88-96.

CEBRIÁN HERREROS, Mariano: " Estrategia multimedia de la televisión en Operación Triunfo". Madrid, 2003. Ciencia 3 Distribución.

COLIS, Javier: "Popstars: todo por un sueño". Barcelona, 2002. Plaza \& Janés.

CORTÉS LAHERA, José Ángel: " La estrategia de la seducción. La programación en la neotelevisión". Pamplona, 1999. Eunsa.

El anuario de la televisión 2001. Madrid, 2001. GECA.

El anuario de la televisión 2001. Madrid, 2002. GECA.

El anuario de la televisión 2001. Madrid, 2003. GECA.

El anuario de la televisión 2001. Madrid, 2004. GECA.

El anuario de la televisión 2001. Madrid, 2005. GECA.

El anuario de la televisión 2001. Madrid, 2006. GECA. 
04/01/2004.

http:/ / www.elmundo.es/papel/2004/01/04/cronica/1552086.html.

HUERTA FLORIANO, Miguel Ángel: "¿La vida en directo?: Realidad y ficción en Gran Hermano". En SANGRO, Pedro, SALGADO, Alejandro: El entretenimiento en TV: guión y creación de formatos de humor en España. Barcelona, 2008. Alertes. Págs. 125-138.

LACALLE, Charo: "El espectador televisivo. Los programas de entretenimiento". Barcelona, 2001. Gedisa.

MARTÍN-LUNAS, Milagros: "Dieciséis jóvenes tras la estela de Marlon Brando". En: El $\quad$ Mundo, 28/04/2002. Disponible en http:/ / www.elmundo.es/2002/04/28/comunicacion/1136436.html.

PEDRERO ESTEBAN, Luis Miguel: "Armas de seducción catódica: Los géneros de entretenimiento en la neotelevisión contemporánea". En SANGRO, Pedro; SALGADO, Alejandro: El entretenimiento en TV: guión y creación de formatos de humor en España. Barcelona, 2008. Alertes. Págs. 33-53.

PRADO, Emili: "La espectacularización de la realidad". En: El anuario de la televisión 2003. Madrid, 2003. GECA. Págs. 178-186.

RTVE: "El enemigo en casa", nuevo concurso para las tardes de TVE. Nota de prensa, 22/04/2005. Disponible en http:// www.rtve.es/FRONT_SALA_PRENSA/?go=eacaa4148f48af89730076a6669df 2169fcb5b71e1aa29dad5e8ff7814161a1919ae0a69cbf3a6804fd809800664a030 
de televisión". Barcelona, 2003. Gedisa.

T.B.G.: 'El gladiador', de Ramón García, sustituye a 'El precio justo' en TVE-1. En: El País, 04/02/2002. Disponible en http://www.elpais.com/articulo/Pantallas/gladiador/Ramon/Garcia/sustituye/p recio/justo/TVE-1/elpepirtv/20020204elpepirtv_2/Tes.

TIJERAS, Ramón: " Las guerras del pirulí. El negocio de la televisión pública en la España democrática". Barcelona, 2005. Debate.

Entrevista: Víctor Martín, productor ejecutivo de programas de entretenimiento de Globomedia, 16/06/2008, Madrid. 